\title{
Regarding "PET/CT Imaging Characteristics After Radioembolization of Hepatic Metastasis from Breast Cancer"
}

\author{
William A. Dezarn ${ }^{1}$
}

Received: 12 December 2019/Accepted: 18 December 2019/Published online: 2 January 2020

(C) Springer Science+Business Media, LLC, part of Springer Nature and the Cardiovascular and Interventional Radiological Society of Europe (CIRSE) 2020

\section{To the Editor}

I approached "PET/CT Imaging Characteristics After Radioembolization of Hepatic Metastasis from Breast Cancer" [1] with interest since I was searching for data on patient response to Yttrium-90 radioembolization. Unfortunately, I had to stop reading the article after reading the "Radioembolization Technique" section. The mixing of dose and activity units is a practice that must stop. The SI unit of activity is the becquerel $(\mathrm{Bq}$, decay per unit time, $\mathrm{s}^{-1}$ ), whereas the unit of radiation dose is the gray (Gy, absorbed energy per unit mass, $\mathrm{J} \mathrm{kg}^{-1}$ ). The biological response of tissue to a given radiation dose depends on the gray given and not the becquerel. Using the simplest dosimetry model of Yttrium-90 gives [2]

$D[\mathrm{~Gy}]=\frac{49.38 A_{0}[\mathrm{GBq}]}{m[\mathrm{~kg}]}$

where $\mathrm{D}$ is dose, A is activity, and $\mathrm{m}$ is the mass of tissue the activity is deposited into.

It is no wonder that Fig. 3 of the article shows no difference in objective response since activity instead of dose was considered. If you have the same activity and deposit it into two different masses, the second being twice the first, the second mass will have half the dose.

I am a vocal proponent of radioembolization, but until we, the medical community, can report the proper predictors of response, this therapy modality will languish in

William A. Dezarn

wdezarn@wakehealth.edu

1 Department of Radiation Oncology, Medical Center Boulevard, Wake Forest University School of Medicine, Winston-Salem, NC 27157, USA obscurity. What is really an insufficient dose delivered to obtain a desired response will be interpreted as an ineffective therapy.

Funding This study was not supported by any funding.

\section{Compliance with Ethical Standards}

Conflict of interest The authors declare that they have no conflict of interest.

Ethical Approval This article does not contain any studies with human participants or animals performed by any of the authors.

Informed Consent For this type of study, informed consent is not required.

Consent for Publication For this type of study, consent for publication is not required.

\section{References}

1. Deipolyi AR, England RW, Ridouani F, et al. PET/CT imaging characteristics after radioembolization of hepatic metastasis from breast cancer. Cardiovasc Intervent Radiol. 2019. https://doi.org/ 10.1007/s00270-019-02375-7.

2. Dezarn WA, Cessna JT, DeWerd LA, et al. Recommendations of the American Association of Physicists in medicine on dosimetry, imaging, and quality assurance procedures for $90 \mathrm{Y}$ microsphere brachytherapy in the treatment of hepatic malignancies. Med Phys. 2011;38(8):4824-45.

Publisher's Note Springer Nature remains neutral with regard to jurisdictional claims in published maps and institutional affiliations. 